\title{
Combustion and emission characteristics of a dual injection system applied to a DISI engine
}

\author{
Byungdeok In, Sangwook Park, Hyungmin Kim and Kihyung Lee* \\ Hanyang University, Gyeonggi 426-719, Korea \\ (C) China University of Petroleum (Beijing) and Springer-Verlag Berlin Heidelberg 2014
}

\begin{abstract}
Concerns about environmental pollution and energy shortages have increased worldwide. One approach to reduce $\mathrm{CO}_{2}$ emissions from gasoline engines is to achieve stratified charge combustion with various injection ratios using port fuel injection (PFI) and direct injection. The combustion and emission characteristics of a 4-valve direct injection spark ignition (DISI) engine equipped with a dual injection system were investigated while the injection ratio was varied. When the direct injection ratio increased, the lean limit $A / F$ was extended. This suggests that the dual injection gasoline engine with both PFI and direct injection can meet severe vehicle emission and fuel economy requirements. The dual injection system had higher combustion pressure than that of either a conventional or direct injection systems. Therefore, the engine power of a dual injection DISI engine would be higher than that of a single injection DISI engine. However, $\mathrm{NO}_{x}$ emissions increased compared with the emission levels in both PFI and DISI systems.
\end{abstract}

Key words: Direct injection spark ignition (DISI), injection ratio, lean burn combustion, stratified combustion, lean limit $A / F$

\section{Introduction}

Recently, demands for better fuel efficiency and lower emission levels have increased to cope with strengthened global emission standards such as the SULEV (Super Ultra Low Emission Vehicle), CAFE (Corporate Average Fuel Economy) and the Kyoto Protocol. Such emission regulations have led to substantial efforts to develop lowemission engine technologies. As a result of these efforts, a direct injection (DI) gasoline engine has recently been developed as a new gasoline injection concept. However, the DI gasoline engine requires lean $\mathrm{NO}_{x}$ catalyst and expensive control technologies. The main drawback of the lean burn engine is that a complex catalytic converter system is required to reduce $\mathrm{NO}_{x}$ emissions. Lean burn engines do not work well with modern 3-way catalytic converters which require a pollutant balance at the exhaust manifold so they can carry out oxidation and reduction reactions - so most modern engines run at or near the stoichiometric point. Alternatively, ultra-lean ratios can reduce $\mathrm{NO}_{x}$ emissions. A high hydrocarbon (HC) or soot emission level is an additional concern due to poor understanding of combustion phenomena in the DI gasoline engine system (Koike et al, 2000). Despite these problems, the DI gasoline engines have around 15\%-

*Corresponding author. email: hylee@hanyang.ac.kr

Received January 7, 2014
$20 \%$ higher thermal efficiencies compared to those of port fuel injection (PFI) engines due to increased compression ratios. The thermal efficiency of the DI gasoline engine is equivalent to that of an indirect-injection diesel engine. In addition, stratified lean burn combustion can be implemented in DI gasoline engines so carbon monoxide (CO) and nitrogen oxide $\left(\mathrm{NO}_{x}\right)$ emissions can be reduced (Ohm et al, 1997; Cho et al, 1996; Cho et al, 2000). Therefore, stratified combustion is extremely significant to the improvement of fuel consumption and emission characteristics in the DI gasoline engine.

With this motivation in mind, a dual injection engine system which consists of two injectors installed at the intake port and the engine cylinder is constructed in this study. The system can take advantage of DI gasoline engines by achieving stratified lean burn combustion, while the port injection system can minimize any disadvantage of the DI gasoline engine (Ikoma et al, 2006). The effects of injection ratio and timing of the dual injectors on the combustion and emission characteristics of the system are investigated. Optimal injection ratio and timing conditions that can create a stratified mixture around the spark plug to accomplish lean burn combustion is proposed in this study.

Taking account of the importance of injection ratio and injection timing, the effect of DI injection ratio on the lean combustion performance was also investigated by onedimensional (1D) simulation analysis. The accuracy of the 
simulation result is validated by experimental results. From the simulation result, we find that the simulation technique is very useful to predict the lean burn performance and save time to analyze the effect of various parameters on the lean burn characteristics.

\section{Experimental apparatus and simulation method}

\subsection{Experimental apparatus}

Fig. 1 shows a schematic diagram of the $500 \mathrm{cc}$ four-valve single cylinder engine used in this study and the specifications of the engine are summarized in Table 1 and the experimental conditions are listed in Table 2. A direct injection-type gasoline injector was installed in the side of the cylinder, and the intake port was equipped with a commercial PFI injector. The specifications of the two injectors are presented in Tables 3 and 4, respectively. Injectors could be controlled independently using a calibration ECU (M800, Control Work Co.) such that the injection timing and injection quantity were able to be precisely controlled.

Table 1 Specifications of a dual DISI engine

\begin{tabular}{cccc}
\hline Engine & $\begin{array}{c}\text { Bore } \times \text { stroke } \\
\mathrm{mm} \times \mathrm{mm}\end{array}$ & $\begin{array}{c}\text { Displacement volume } \\
\mathrm{cc}\end{array}$ & $\begin{array}{c}\text { Compression } \\
\text { ratio }\end{array}$ \\
\hline $\begin{array}{c}4 \text { stroke single cylinder, } \\
\text { direct injection system }\end{array}$ & $82 \times 93.5$ & 500 & 11.5 \\
\hline
\end{tabular}

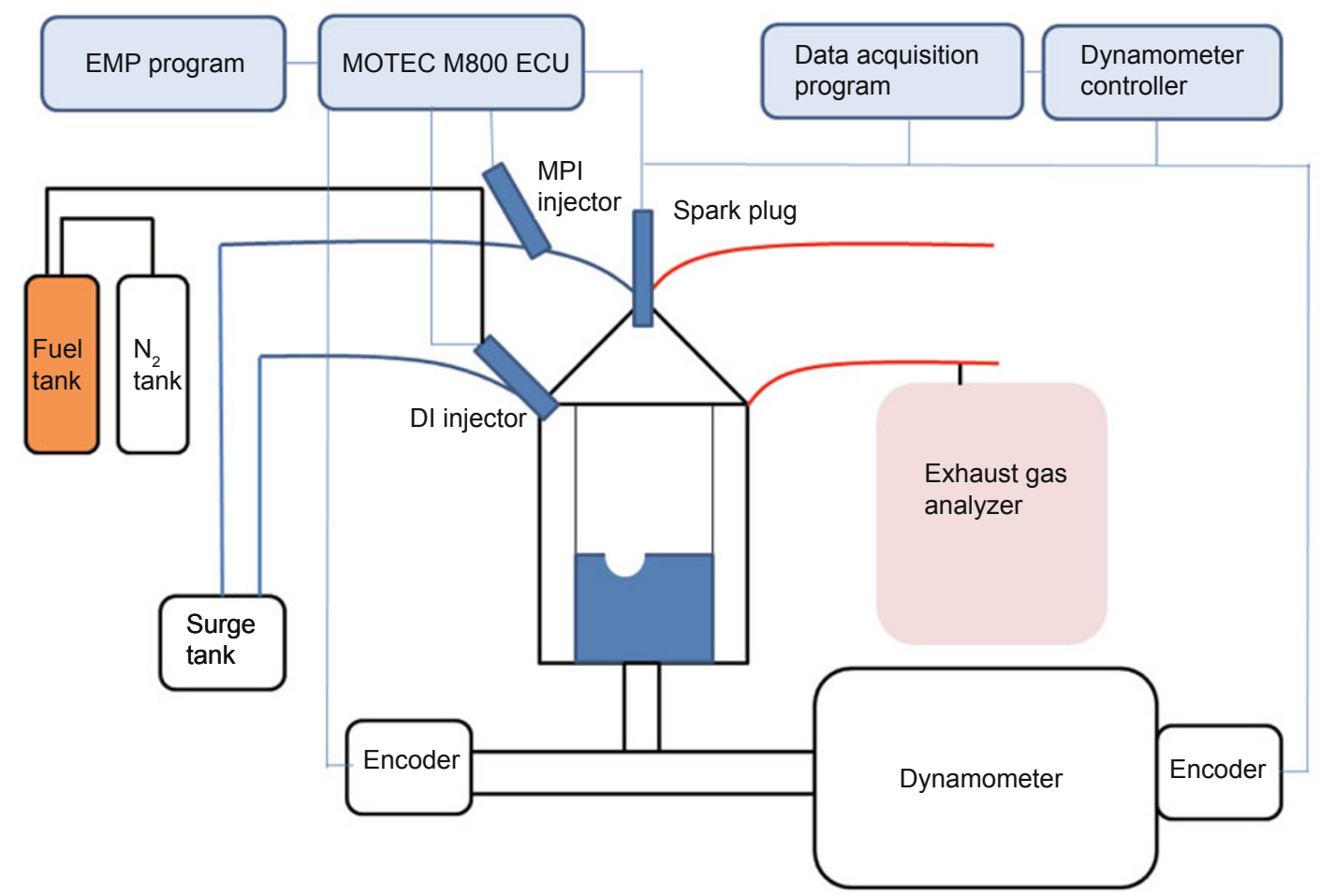

Fig. 1 Schematic of the dual injection type DISI engine and dynamometer system

Table 2 Experimental conditions for engine performance

\begin{tabular}{|c|c|c|c|c|c|c|c|c|}
\hline \multirow{2}{*}{$\begin{array}{l}\text { Engine } \\
\text { speed, rpm }\end{array}$} & \multirow{2}{*}{$\begin{array}{l}\text { Load } \\
\mathrm{MPa}\end{array}$} & \multicolumn{2}{|c|}{ Injection pressure, $\mathrm{MPa}$} & \multicolumn{2}{|c|}{ Injection timing } & \multirow{2}{*}{$\begin{array}{l}\text { Intake } \\
\text { condition }\end{array}$} & \multirow{2}{*}{ Fuel } & \multirow{2}{*}{$\begin{array}{c}\text { Direct injection } \\
\text { ratio, } \%\end{array}$} \\
\hline & & PFI & DISI & PFI & DISI & & & \\
\hline 2000 & 0.3 & 0.3 & 10 & $\begin{array}{c}\text { BTDC } 540^{\circ}, 360^{\circ}, 270^{\circ}, \\
180^{\circ}, 90^{\circ}, 60^{\circ}, 45^{\circ}\end{array}$ & $\begin{array}{l}\text { BTDC } 180^{\circ}, \\
90^{\circ}, 60^{\circ}, 45^{\circ}\end{array}$ & $\begin{array}{c}\text { Natural } \\
\text { aspiration }\end{array}$ & Gasoline & $10-90$ \\
\hline
\end{tabular}

Table 3 Specifications of the DISI engine injector

\begin{tabular}{ccccc}
\hline Injector & Spray geometry & Nozzle & $\begin{array}{c}\text { Spray angle } \\
\text { degree }\end{array}$ & $\begin{array}{c}\text { Injection pressure } \\
\text { MPa }\end{array}$ \\
\hline DISI & Hollow cone & Swirl type & 60 & 10 \\
\hline
\end{tabular}

Table 4 Specifications of the PFI engine injector

\begin{tabular}{cccc}
\hline Injector & Spray geometry & Number of holes & Injection pressure, MPa \\
\hline PFI & 2 spray & 4 & 0.3 \\
\hline
\end{tabular}

The injection pressure of the direct injector used was 10 $\mathrm{MPa}$. The injection pressure was maintained at this value using compressed nitrogen gas, which could reduce the pulsation motion caused by the fuel supply. The injector was installed at the cylinder head toward the intake port to achieve stratified combustion, which resulted in extending the limits of combustion. The angle of the injector was determined based on the optimum injection angle of $30^{\circ}$ that was concluded in previous studies of spray characteristics of the injector (Park et al, 2011). It is because this angle is 
well matched with the piston cavity, which helps to bounce the injected fuel to the spark plug. This behavior results in fuel accumulation near the spark plug. Thus, the $30^{\circ}$ angle is useful to create stratification in the cylinder (Park et al, 2011). Fig. 2 shows the cavity shape of the piston. The cavity was machined in the piston to reduce collision of the injected fuel from the direct injector with the piston so that the second atomization and stratification were facilitated. The compression ratio was set at 11.5.

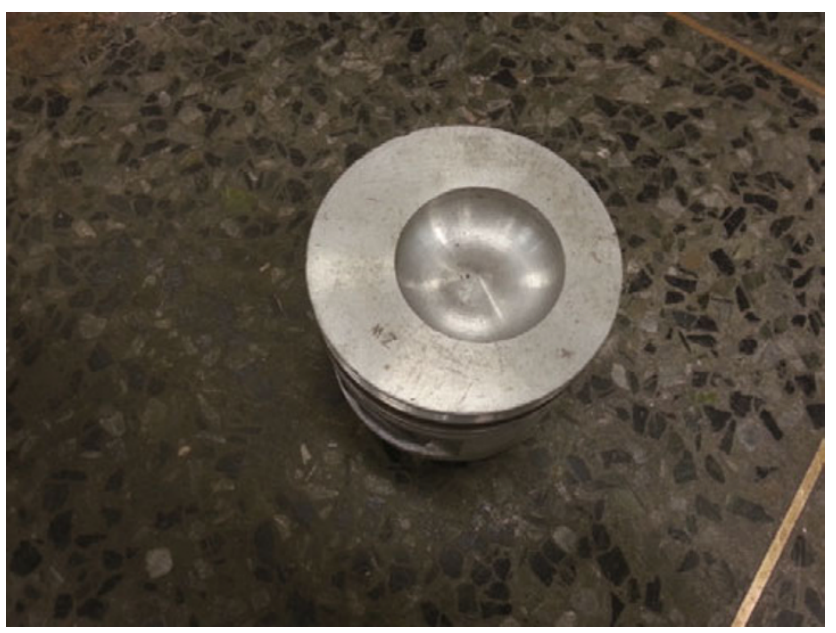

Fig. 2 Photograph of the piston

A low pressure gasoline pump was employed to achieve an injection pressure of $0.3 \mathrm{MPa}$ for the port injection, and a commercial gasoline injector usually employed in gasoline engines was used in this study. The PFI injector was installed at the intake port with an angle of $45^{\circ}$, at which the wall wetting was the lowest because this angle is best to reduce the amount of fuel impinged on the intake port wall. The engine speed and load were controlled using an EC dynamometer (EC-150). The intake chamber was equipped with a throttle position sensor (TPS) and manifold absolute pressure (MAP) sensors to measure the intake air quantities. A temperature sensor was installed at the exhaust port to measure the exhaust gas temperature, which corresponds to the combustion temperature, and an $\mathrm{O}_{2}$ sensor was also used to control the air-fuel ratio and to evaluate the lean limit air-fuel ratio $(A / F)$. In addition, the emission characteristics were also investigated using a gas analyzer (Greenline 9000, Eurotron). A spark plug type pressure sensor (6052B, Kistler) was attached in the center of the cylinder head and was used to measure the pressure in the cylinder. The data were collected using an $\mathrm{A} / \mathrm{D}$ board in real time, and timing data for the combustion analysis, that is, TDC ( $Z$-phase) and $360^{\circ} \mathrm{crank}$ angle ( $A$-phase) signals, were obtained from an encoder. The engine load was determined from torque data obtained using load cells in the engine dynamometer. A steady flow test was conducted to measure the tumble ratio of the intake port. The cylinder head used in the steady flow test was the same as the engine performance test. Also, a valve lift controller using a dial gauge was used to precisely adjust valve lift. An orifice flow meter, which can be easily made and has an excellent accuracy, was fabricated to measure the intake air flow rate.
The schematic diagram of the steady flow test is presented in Fig. 3.

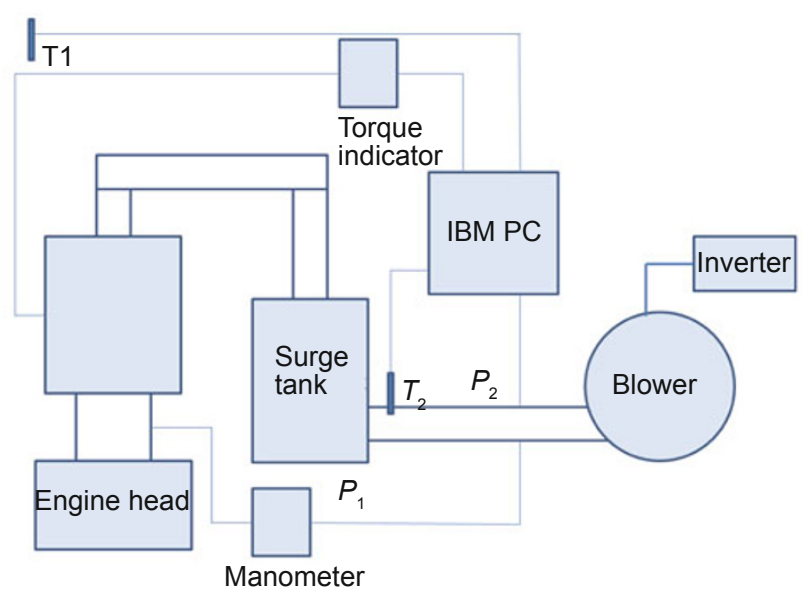

Fig. 3 Schematic diagram of the steady state flow test

The orifice flow meter uses the Venturi principle of the pressure difference created as a fluid flows through a restriction. This differential pressure is related to the flow rate. In this study, by setting the limited differential pressure $\left(\Delta P_{1}\right)$ at $300 \mathrm{mmAq}$, the flow rate of intake air was calculated by measuring differential pressure $\left(\Delta P_{2}\right)$ before and after intake of air until the differential pressure between pressure inside the cylinder created by the vacuum pump and atmospheric pressure becomes $\Delta P_{1}$. The calculation equation is described as follows:

$$
G_{a}=\varepsilon \alpha F_{0} \sqrt{2 g \gamma_{2} \triangle P_{2}}
$$

where $G_{\mathrm{a}}$ is the mass flow rate; $\varepsilon$ is the expansion coefficient; $\gamma_{2}$ is the specific gravity; $\alpha$ is the orifice flow coefficient; $\Delta P_{2}$ is the differential pressure before and after intake of air

In addition, the tumble ratio is defined as:

$$
\left\{\begin{array}{l}
T R_{z}=\frac{\sum_{i=1}^{n} m_{i}\left[\left(y_{i}-y_{c}\right) u_{i}-\left(x_{i}-x_{c}\right) v_{i}\right]}{\frac{2 \pi N}{60} \sum_{i=1}^{n}\left[\left(x_{i}-x_{c}\right)^{2}+\left(y_{i}-y_{c}\right)^{2}\right]} \\
T R_{y}=\frac{\sum_{i=1}^{n} m_{i}\left[\left(y_{i}-y_{c}\right) w_{i}-\left(z_{i}-z_{c}\right) v_{i}\right]}{\frac{2 \pi N}{60} \sum_{i=1}^{n}\left[\left(y_{i}-y_{c}\right)^{2}+\left(z_{i}-z_{c}\right)^{2}\right]}
\end{array}\right.
$$

where $T R_{z}$ is the tumble ratio of the $z$ axis; $T R_{y}$ is the tumble ratio of the $y$ axis; $m$ is the mass flow rate; $n$ is the number of cells; $N$ is the engine speed, rpm; $v$ is the cumulative drop size distribution; $w$ is the velocity component of the generic cell.

\subsection{Experimental conditions and procedure}

The engine test conditions were an engine speed of 2,000 rpm and a brake mean effective pressure (BMEP) of 0.3 $\mathrm{MPa}$, which are typical lean-burn operating conditions, and the ignition timing was fixed at $30^{\circ}$ before top dead center (BTDC) to compare the combustion characteristics in every case under the same experimental conditions. In addition, the 
injection timing for the port fuel injector was varied between $540^{\circ}, 360^{\circ}, 270^{\circ}, 180^{\circ}, 90^{\circ}, 60^{\circ}$ and $45^{\circ}$ BTDC to evaluate the lean burn characteristics, and the injection timing for the direct injector was varied between $180^{\circ}, 90^{\circ}, 60^{\circ}$ and $45^{\circ}$ BTDC to identify the formation of homogeneous mixture and stratification mixture. Fig. 4 indicates a comparison of the injection timings for two injectors. The air-fuel ratio $(A / F)$ was controlled by fixing the volume flow rate of the intake air while the fuel was gradually reduced. In this study, we changed the amount of fuel to be BMEP 0.3 MPa under a fixed throttle angle condition. We continued the experiment for obtaining $A / F$ until the combustion stability ( $C O V_{\text {imep, }}$, coefficient of variability of mean effective pressure, is used to indicate the combustion stability) reached $5 \%$. In this way, $C O V_{\text {imep }}$ values were measured, and the lean burn characteristics were investigated. A $C O V_{\text {imep }}$ of less than $5 \%$ was defined as a stable lean burn range in this study.

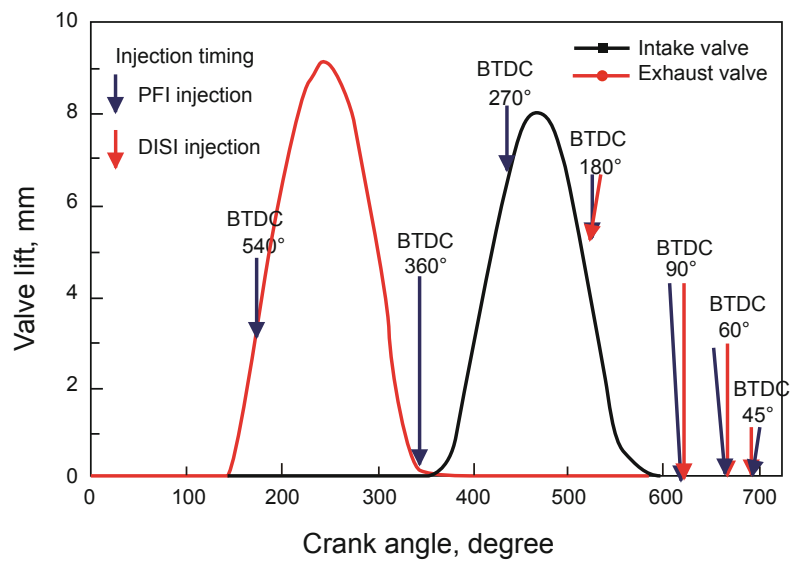

Fig. 4 Various injection timings for the DISI engine system and the PFI engine system

\subsection{Simulation model}

A simulation was carried out using WAVE software (Ricardo). Fig. 5 shows a schematic of the engine simulation model. The combustion modeling used for simulation was the SI WIEBE, a function widely used to describe the rate of fuel mass burn in thermodynamic calculations. The cumulative mass fraction burned as a function of crank angle is given by:

$$
W=1.0-\exp \left[-A W I\left(\frac{\theta}{B D U R}\right)^{(W E X P+1)}\right]
$$

where $A W I$ describes an internally calculated parameter that allows $B D U R$ (best-fit Wiebe burn duration) to cover a range between $10 \%$ and $90 \% ; \theta$ is the crank angle after start of combustion; $B D U R$ is a user-entered combustion duration between 10\% and 90\%; and WEXP (best-fit Wiebe exponent) is a user-entered exponent in the Wiebe function.

In a direct injection spark ignition (DISI) case, the fuel and air are not fully mixed at the start of combustion. In the early stages of combustion, specifically from the start of combustion up to a mass fraction equal to the userentered value for "start of air entrainment," the user-entered "combustion equivalence ratio" is used.

$$
\frac{A}{F}=\left(\frac{A}{F}\right)_{\text {stoich }} / \varphi_{\text {burn }}
$$

where $A$ is the weight of air; $F$ is the weight of fuel; $(A / F)_{\text {stoich }}$ is the air-fuel ratio of stoichiometric combustion; $\varphi$ is the equivalence ratio.

The mixing algorithm for the sub-model then gradually adjusts the stoichiometric combustion during combustion so that the entire charge of fuel and air is consumed by the end of combustion. This algorithm is:

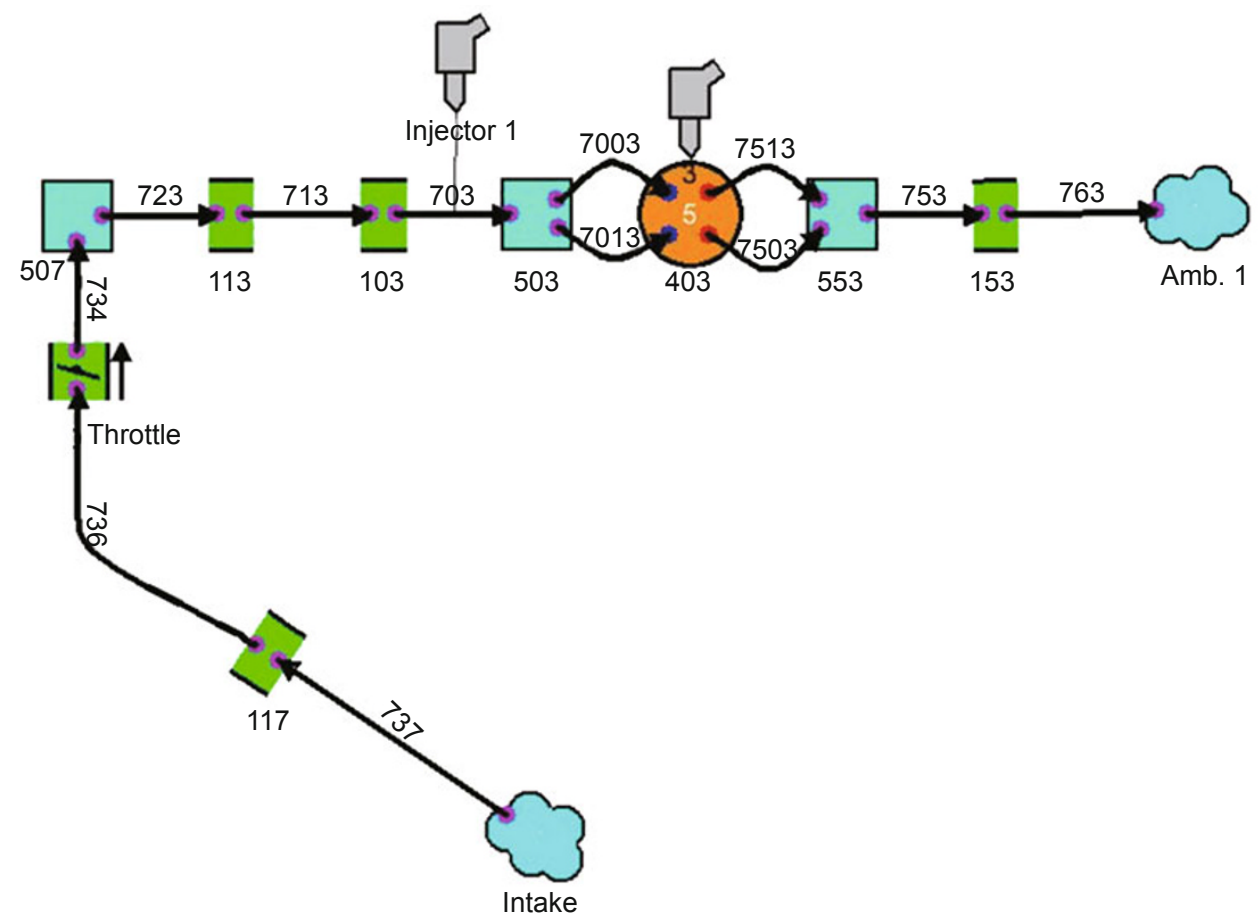

Fig. 5 Schematic of the engine model 


$$
\frac{A}{F}=\left(1-M_{\text {ratio }}\right) \cdot \frac{\left(\frac{A}{F}\right)_{\text {stoich }}}{\varphi_{\text {burn }}}+M_{\text {ratio }} \frac{A_{\text {rem }}}{F_{\text {rem }}}
$$

where $M_{\text {ratio }}$ is the mole fraction of $A / F$ ratio; $A_{\text {rem }}$ is the weight of the removed air; $F_{\text {rem }}$ is the weight of the removed fuel.

\section{Results and discussion}

\subsection{Spray behavior and tumble ratio characteristics of the direct injector}

Fig. 6 shows non-dimensional tumble ratio with valve lift. The intake port used shows a strong tumble flow. From this result, we found that it is the most suitable shape intake port for a lean burn engine. Fig. 7 shows the spray behavior of the direct injector used when the pressure was varied. This experiment was conducted to obtain information about the effect of injection timing on spray pattern. As shown in Fig. 7, the spray penetration and spray angle decreased with increasing pressure. The higher pressure corresponded to the cylinder pressure of the compression stroke. This trend coincides with the results observed by other researchers (Lee et al, 2006; Jeon et al, 2010; Park et al, 2011). These results may be attributed to a decrease in the kinetic energy of fuel droplets resulting from an increase in the density of air. Since high pressure helped to decrease penetration and spray angle, it was hard to spread in the cylinder widely. This phenomenon caused the formation of stratified mixtures. Therefore, it is expected that a locally rich mixture could be formed as a result of the high pressure, especially late in the compression stroke. From this spray visualization result, we found that injection timing had a great effect on spray behavior and it is important to select injection timing to form a rich mixture near the spark plug called stratification.

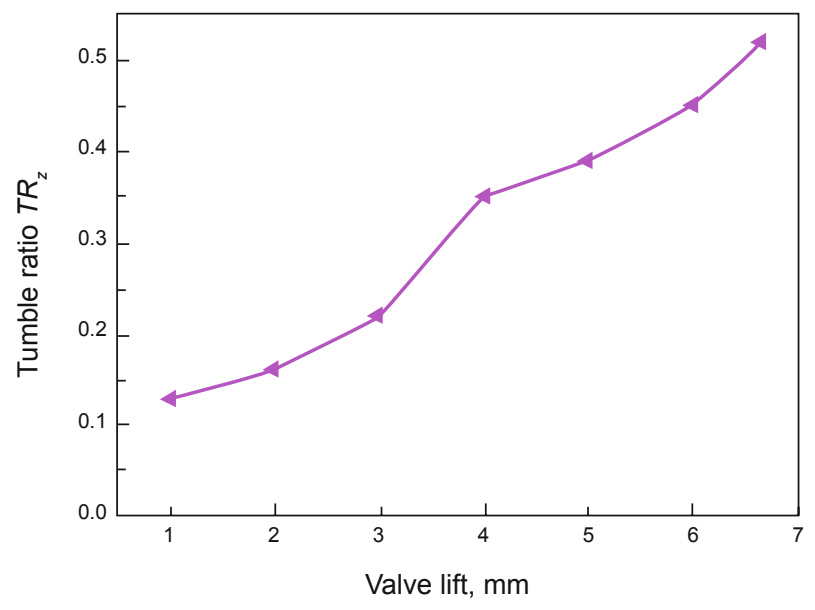

Fig. 6 Tumble ratio $\left(T R_{\mathrm{z}}\right)$ according to valve lift

\subsection{Combustion stabilities of single injection case}

Fig. 8 shows the effect of injection timing on the lean limit $A / F$ only using the PFI injector. In this figure, $C O V_{\text {imep }}$ of less than $5 \%$ was defined as a lean limit $A / F$.

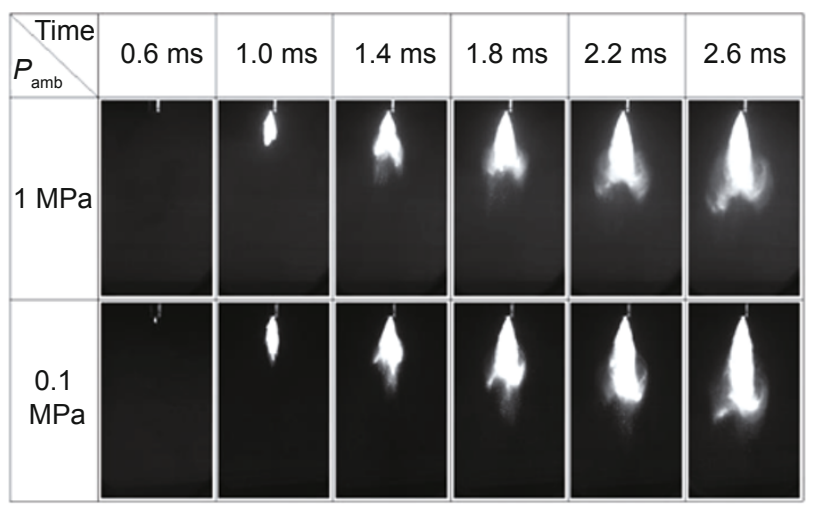

Fig. 7 Spray behavior at different pressures

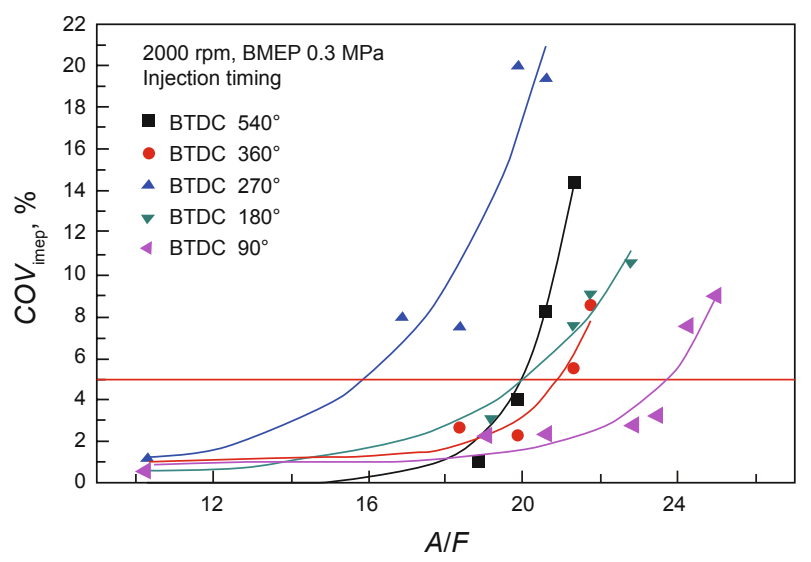

Fig. 8 Effect of injection timing on the lean limit $A / F$ using the PFI system

As can be seen from Fig. 8, it is clear that the lean limit $A / F$ varies with the injection timing. The lean limit $A / F$ was extended as the fuel was injected earlier before intake valve opened. This means that injected fuel had enough time to mix and evaporate in the intake port prior to intake valve opening. In case of the PFI injector, the lean limit $A / F$ region was greatly affected by injection timing and the maximum lean limit $A / F$ was 24 . From these results, we found that early injection timing which contributed to the formation of homogeneous mixtures was effective to extend the lean limit $A / F$.

Fig. 9 shows a comparison of the burn rate between the same injection timings as the result of lean limit $A / F$ using the PFI injector system. As shown in Fig. 9, BTDC $90^{\circ}$ which had a large lean limit $A / F$ indicated the shortest burn rate. The formation of a uniform mixture caused by early injection timing made the burn rate high and this phenomenon resulted in extending the lean limit $A / F$ in the PFI injection case.

Next, we investigated the lean limit $A / F$ in the direct injection system to compare with that of the PFI injector system. Fig. 10 shows the effect of injection timing on the lean limit $A / F$ using the direct injection system. As can be seen from Fig. 10, the lean limit $A / F$ increased from that of the PFI case. The lean limit $A / F$ was extended to 29 as the injection timing was retarded to TDC. This late injection timing helped to accumulate the injected fuel near the spark plug area. In other words, the mixture could be stratified 


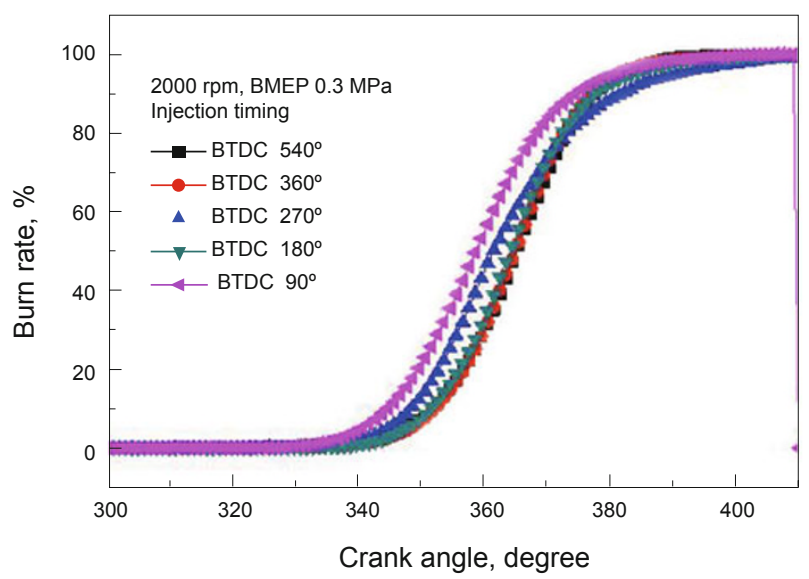

Fig. 9 Effect of injection timing on burn rate using the PFI injection system

at this timing. From these results, we found that the direct injection system was useful to extend the lean limit $A / F$ and it was easy to form stratification in the cylinder. However, the lean limit $A / F$ is still not high enough when using the direct injector. Therefore, we tried to use a dual injection system to obtain a more extended lean limit characteristic.

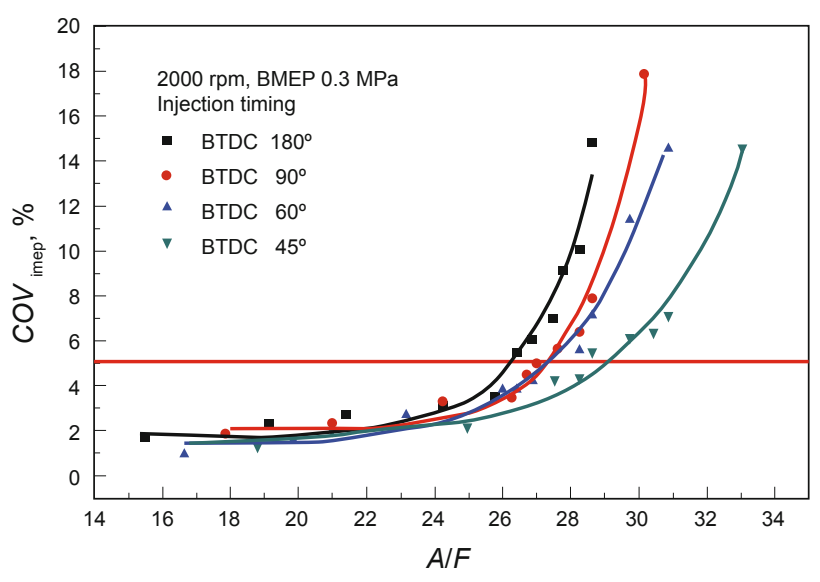

Fig. 10 Effect of injection timing on the lean limit $A / F$ using the direct injection system

Fig. 11 shows the effect of injection timing on the burn rate using the direct injection system. This result revealed that the burn rate became low as the injection timing gets close to TDC. From this figure, we found that stratification caused by late injection contributed to fast combustion. Finally, fast combustion extended the lean limit $A / F$ in the direct injection case.

\subsection{Effect of the direct injection ratio on lean limit $A / F$}

Fig. 12 indicates the lean limit $\mathrm{A} / \mathrm{F}\left(C O V_{\text {imep }}\right.$ less than $5 \%$ ) varies with the injection ratio of the direct injector. A uniform mixture was achieved in the cylinder due to port injection, and a stratified mixture formed around the spark plug with the direct injection. Therefore, it is necessary to investigate the effect of direct injection ratio on the lean limit $A / F$. It is expected that increasing the rate of direct injection

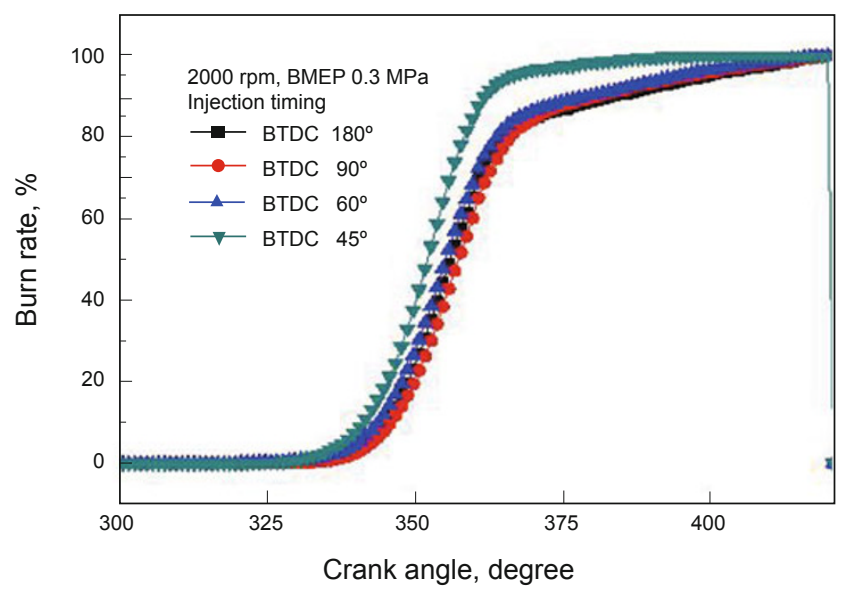

Fig. 11 Effect of injection timing on the burn rate using the direct injection system

helps to form the stratified mixture in the combustion chamber. In addition, the lean limit $A / F$ increased as the injection timing was retarded to TDC at the same injection ratio. The maximum lean limit $A / F$ became 37 , which is an improvement of $54 \%$ and $27 \%$ compared to the PFI and direct injection cases, respectively. This result means that the stratified charge mixture tended to be formed when the injection timing of direct injection was retarded to TDC. These experimental results revealed that the dual injection system was very effective in extending the lean limit $A / F$. In order to confirm the trend of these experimental results, a simulation was conducted in this study.

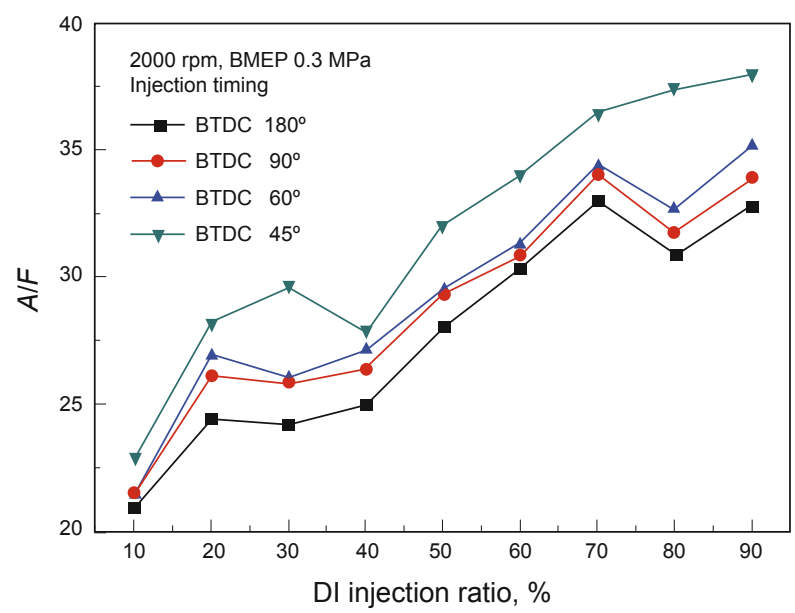

Fig. 12 Effect of direct injection ratio on the lean limit $A / F$ in the dual injection system by experiment

Fig. 13 shows simulation results at the same conditions as Fig. 9. The simulation results are in excellent agreement with the experimental results. The lean limit $A / F$ was observed to increase with an increase in the direct injection ratio. From the experimental and simulation results, we found that the ratio of direct injection had a great effect on the lean limit $A$ / $F$ and the lean limit $A / F$ was extended by retarding the direct injection timing at the same direct injection ratio case. 


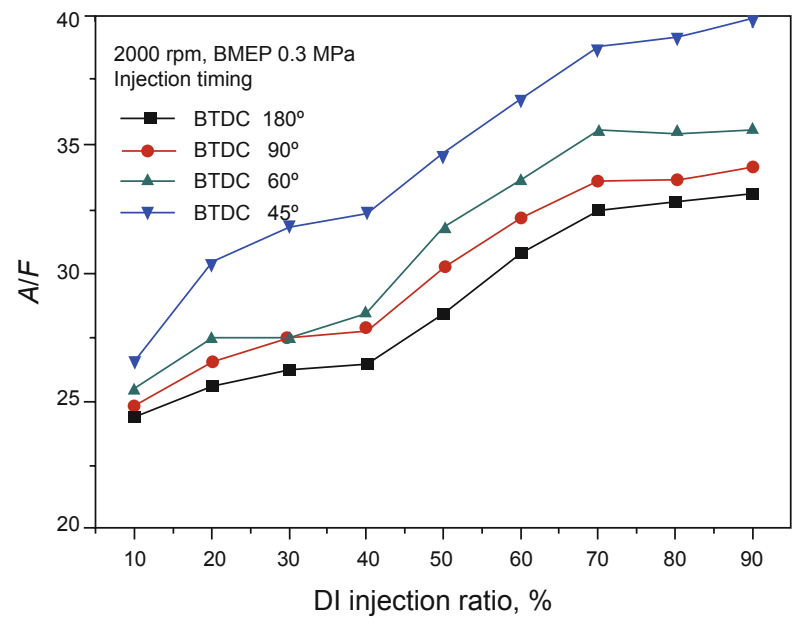

Fig. 13 Effect of direct injection ratio on the lean limit $A / F$ in the dual injection system by simulation

\subsection{Effect of direct injection ratio on combustion pressure}

A disadvantage of direct injection type gasoline engines caused by stratification is to deteriorate engine power due to decreased combustion pressure in the cylinder. To solve this problem, a dual injection strategy is adopted in this study. The maximum combustion pressure is expected to increase with the dual injection system. The in-cylinder combustion pressure was obtained at various mixture conditions. As shown in Fig. 14, the combustion pressure increased as the port injection ratio increased. Increasing the port injection ratio enhanced the formation of a homogeneous mixture in the combustion chamber. Therefore, lower combustion pressure in DI gasoline engines could be compensated by optimizing the port injection ratio. In addition, the combustion pressure was decreased by retarding the direct injection timing. The reason for this trend is that the retarded injection timing is not enough to generate a homogeneous mixture in the combustion chamber.

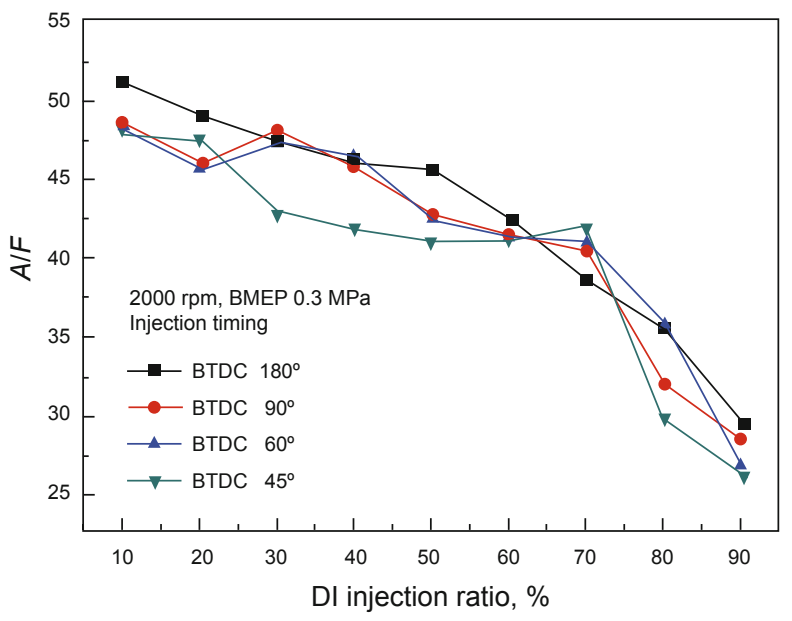

Fig. 14 Effect of direct injection ratio on the combustion pressure in the dual injection system

\subsection{Effect of direct injection ratio on the exhaust emission}

The CO, THC and $\mathrm{NO}_{x}$ emissions were measured in the direct gasoline engine without a catalytic converter and the results are plotted in Fig. 15. As shown in Fig. 15, the CO emission increased with increasing direct injection ratio due to the increased level of incomplete combustion that occurred as a result of the lower combustion temperature and wall-wetting on the surface of the combustion chamber.
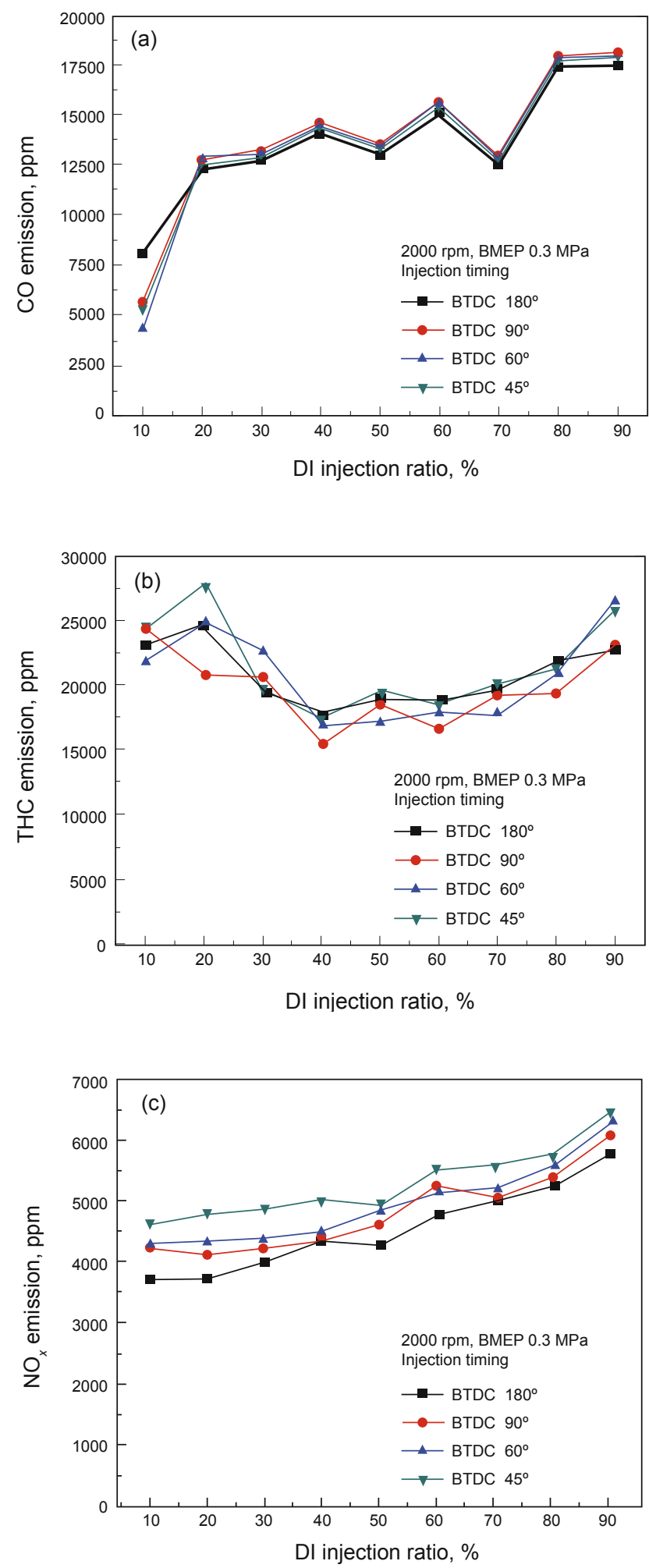

Fig. 15 Effect of injection ratio on the exhaust emission in the dual injection system 
On the other hand, the THC emission decreased as the direct injection ratio increased from $10 \%$ to $40 \%$. After that, the THC emission increased with an increase in the injection ratio. Wall wetting is regarded as the reason for the high THC emission with the high direct injection ratio. In spite of a decrease in the injection ratio from $40 \%$ to $10 \%$, the increase in the THC emission was due to the crevice volume in the combustion chamber.

In addition, the $\mathrm{NO}_{x}$ emissions also increased with increasing direct injection ratio. As the injection timing approached TDC, the $\mathrm{NO}_{x}$ emissions increased due to stratification at high combustion temperature.

\section{Conclusions}

A direct-injection strategy and then a combined port injection and direct injection strategy was applied to a lean burn gasoline engine. The lean limit $A / F$ and emission characteristics were investigated by changing the direct injection ratio. The conclusions obtained can be summarized as follows:

1) The lean limit $A / F$ improved by dual injection system is $54 \%$ and $27 \%$ compared to the PFI and direct injection systems.

2) The lean limit $A / F$ was extended by not only increasing the direct injection ratio but also by setting the direct injection timing close to TDC. This means that stratified mixture is effective in extending the lean limit $A / F$.

3) The combustion pressure was increased using a dual injection strategy, consisting of both direct injection and port injection.

4) $\mathrm{CO}$ and $\mathrm{NO}_{x}$ emissions increased as the portion of directly injected fuel increased. THC emissions tended to increase when the portion of the direct injection was more than $40 \%$. Wall wetting on the surface of the combustion chamber was easily generated under the stratified mixture condition.

\section{Acknowledgements}

This work was supported by the Industrial Strategic Technology Development Program, 10042559, 'Development of fuel injector for 200 bar gasoline direct injection system' funded by the Ministry of Trade, Industry \& Energy (MI, Korea).

\section{References}

Cho G S, Chung Y J and Kim W B. Effect of fuel injection timing on the performance characteristics in an SI engine. Trans. of KSAE. 1996. 4(6): 144-152 (in Korean)

Cho H S, Park T Y, Park S J, et al. Engine operation characteristics of a gasoline direct injection engine. Trans. of KSAE. 2000. 8(5): 54-66 (in Korean)

Ikoma T, Abe S, Sonida Y, et al. Development of V-6 3.5-liter engine adopting new direct injection system. SAE Technical Paper 2006-011259,2006

Jeon C, Jeong J, Kim H, et al. An experimental study of the characteristics of non-evaporating diesel spray from common rail system with ambient pressure. KSAE10-B0034, 2010 (in Korean)

Koike M, Saito A, Tomoda T and Yamamoto. Researchand development of a new direct injection gasoline engine. SAE Technical Paper 2000-01-0530, 2000

Lee C, Lee K, Lim K, et al. An experimental study of the stratified combustion characteristics in a direction injection gasoline engine. Trans. of KSAE. 2006. 14(2): 121-126 (in Korean)

Ohm I Y, Jeong K S and Jeung I S. Effects of injection timing on the lean misfire limit in an SI engine. Trans. of KSAE. 1997.5(5): 97-103 (in Korean)

Park J, Park S, Lee C, et al. Spray behavior characteristics of multihole GDI injector for the injection conditions in a constant volume chamber. KSAE Conference, 2011, 5. 194-197

(Edited by Sun Yanhua) 